\title{
Por uma didática decolonial: epistemologia e contradições
}

\author{
Maria Amélia Santoro Franco ${ }^{1}$ \\ ORCID: 0000-0003-3867-5452
}

\section{Resumo}

Esta pesquisa foi realizada em 2019 e teve a finalidade de responder à questão: qual a didática para a escola básica pública em tempos tão adversos? Utilizou-se como metodologia o bilan de savoir, em sua perspectiva crítica e participativa, com 150 docentes de escola pública, trezentos questionários, três entrevistas, dois grupos de diálogo e uma visita guiada por docentes a duas escolas públicas. Após dupla triangulação e interpretações coletivas, comprovou-se que os dados oferecem indícios de que a didática está associada ao fenômeno ensino, mas que, no entanto, a compreensão e a prática desse fenômeno se cristalizam como atividades dissonantes e desvinculadas das necessidades e urgências do momento atual. 0 trabalho identifica seis componentes dessa dissonância como contradições internas e recomenda que os cursos de formação insistam na presença da didática em uma concepção decolonial e em práticas que busquem ensinar o ensino para os futuros docentes. As contradições encontradas foram: 1. A contradição pedagógica: uma teoria de ensino ou uma teoria da formação? 2. A contradição ontológica: ensino requer relações verticais ou participativas? 3. A contradição prática: didática que quer ensinar versus didática que não pode ensinar. 4. A contradição epistêmica: o aluno não quer aprender; o professor não pode ensinar; o professor quer ensinar, o aluno não consegue aprender. 5. Contradição conceitual: o professor que ensina? 0 aluno que aprende? 6. Contradição ética: enquanto ensino, do meu jeito, do meu modo, excluo gentes; excluo alunos.

\section{Palavras-chave}

Didática - Decolonização - Formação de professores - Escola pública.

$\overline{\text { 1- Universidade Católica }}$ de Santos, Santos, SP, Brasil. Contato: ameliasantoro@uol.com.br 


\section{Towards a decolonial didactics: epistemology and contradictions}

\section{Abstract}

This research was carried out in 2019 and aimed to answer the question: what is the didatics for the public elementary school in such adverse times? The methodology used was the bilan de savoir, in its critical and participatory perspective, with 150 public school teachers, three hundred questionnaires, three interviews, two dialogue groups and a visit to two public schools guided by teachers. After double triangulation and collective interpretations, it was proven that the data provide evidence that didactics is associated with the teaching phenomenon, but that, however, the understanding and practice of this phenomenon crystallize as dissonant activities and disconnected from the needs and urgencies of the present moment. The work identifies six components of this dissonance as internal contradictions and recommends that training courses insist on the presence of didactics in a decolonial conception and on practices that seek to teach the teaching practice to future teachers. The contradictions found were: 1. The pedagogical contradiction: a teaching theory or a formation theory? 2. The ontological contradiction: does teaching require vertical or participatory relationships? 3. The practical contradiction: didactics that want to teach versus didactics that cannot teach. 4. The epistemic contradiction: the student does not want to learn; the teacher cannot teach; the teacher wants to teach, the student cannot learn. 5. Conceptual contradiction: the teacher who teaches? The student who learns? 6. Ethical contradiction: while teaching, in my way, in my manner, I exclude people; I exclude students.

\section{Keywords}

Didactics - Decolonization - Teacher training - Public school.

\section{Introdução}

A causa fundamental do desenvolvimento dos fenômenos não é a externa, mas interna; ela reside no contraditório do interior dos próprios fenômenos. (TSÉ-TUNG, 2008, p. 86).

Neste texto, compartilho alguns resultados de uma pesquisa ${ }^{2}$ que teve a proposta de responder: Qual a didática para a escola básica pública em tempos tão adversos? Onde está a didática na escola pública?

2- 0s dados que fundamentam os resultados não estão totalmente disponíveis publicamente, apenas a síntese, conforme adequado à proposta metodológica. Aqueles que desejam mais detalhes podem solicitá-los pelo e-mail acadêmico da autora. 
Considerei que seria relevante uma pesquisa nessa direção, desde que eu, como pesquisadora, conseguisse compreender a perspectiva do docente da escola pública de hoje, além dos discursos já postos e dos resultados já percebidos em trabalhos anteriores.

A proposta era para que eu considerasse os tempos atuais, na perspectiva de sua adversidade. Assim, minhas preocupações iniciais focaram a questão metodológica e a questão do contexto temporal. 0 método deveria provocar uma reflexão nos docentes que fariam parte da pesquisa e produzir a participação deles tanto na perspectiva de disponibilizar dados de reflexão quanto para ajudar a ler a escola atual e interpretar as reflexões dos demais sujeitos. Com relação ao tempo histórico adverso, foi preciso recuar um pouco no tempo e problematizar alguns momentos que demarcaram sinais perceptiveis nos sentidos de escola.

Nas décadas finais do século passado, fui diretora de escola pública. Essa vivência me ajudou a identificar, na pesquisa, os tempos e os complexos meandros que perpassam uma instituição social; neste caso, a escola pública. Essa situação fez-me refletir: Houve tempos menos adversos para a escola pública? Menos complexos? 0 que caracteriza a complexidade do tempo atual?

Aprofundando o olhar, considerei que cada tempo histórico segue uma lógica específica, porque é organizado conceitualmente por sujeitos condicionados em subjetividades temporais. No entanto, o tempo atual se torna mais cruel quando se organiza em torno da lógica neoliberal, nos contornos da supremacia do mercado financeiro e em detrimento das perspectivas humanistas e de valores de solidariedade e participação do sujeito nos rumos da sociedade em que vive. Essa consideração me leva a reforçar a fala de Mia Couto: "Não precisamos de mais tempo. Precisamos de um tempo que seja nosso!" (informação verbal) ${ }^{3}$.

0 escritor queria nos alertar que o fundamental é o protagonismo do sujeito em significar seu tempo, ou seja, em perceber as coisas no significado de seu tempo. Penso que muito incomoda perceber-se como pouco autônomo em compreender que os significados históricos que atribuímos a fenômenos que nos cercam cheguem a ser reinterpretados, por outros, de forma abrupta, invasiva ou não conceitual. São muitos os exemplos, mas realço a questão da escola. Para que serve a escola atual? É para passar a matéria ou para formar sujeitos? Percebemos que, para a lógica neoliberal, a função da escola é transmitir informação e não mais para formar alunos. Essa situação de desconforto quanto ao significado da escola vai nos deslocando arbitrariamente de nosso próprio tempo. Isso não significa desprezar a ideia de que tudo esteja em permanente transformação; o próprio sentido da escola está! No entanto, espera-se que os sujeitos que viveram e estudaram a escola percebam-se como participantes das transformações que ocorrem em seus significados e daquelas que precisam ocorrer.

Por fim, para este trabalho, considerei, que tempos adversos seriam considerados como tempos de pouca autonomia do próprio sujeito na significação de seu tempo histórico; considerei também que tempos adversos são tempos pouco democráticos, autoritários, de massificação de respostas, de poucas possibilidades de inventarmos nosso próprio tempo.

3- Fala proferida por Mia Couto no ciclo de conferências Fronteiras do pensamento em Florianópolis, em agosto de 2014. 
Olhando em retrospectiva, avaliei que, nas décadas finais do século passado, as teorias crítico-reprodutivistas foram fundamentais para a compreensão sobre a escola. Trago para este texto alguns contrapontos históricos para perceber que aquele momento após as ditaduras da Europa e do $\mathrm{Brasil}^{4}$, parecem ter produzido profundas ressignificações no sentido da escola pública. Assim, os objetivos deste artigo são: a) considerar alguns contrapontos teórico-históricos que ajudam a compreender o contexto atual das escolas públicas no Brasil; b) explicitar a metodologia do trabalho que permitiu identificar alguns sentidos das relações do professor da escola pública com o saber didático; c) analisar os componentes necessários para a compreensão da contradição interna do fenômeno didático; e d) propor a didática decolonial como forma de resistência e recriação de práticas democráticas da e na escola pública.

\section{Tempos de escola pública}

A escola pública brasileira traz marcas profundas da educação jesuítica. Sua presença preponderou no Brasil por 149 anos, desde 1549 até a expulsão da Companhia de Jesus, por obra do marquês de Pombal, em 1759, seguindo a perspectiva do projeto político-econômico de Portugal.

No entanto, mesmo após a expulsão dos jesuítas, a situação pedagógica pouco mudou, uma vez que o ensino continuou elitista, enciclopédico, com objetivos de mera ilustração e boa memorização e com métodos pedagógicos autoritários e disciplinadores, o que acabou por desenvolver, nos estudantes, a passividade, a submissão às autoridades e aos modelos ultrapassados. As reformas pombalinas, portanto, parecem ter meramente retirado a educação pública do poder da Igreja, passando-a ao Estado, na perspectiva de uma educação gratuita e laica.

As raízes pedagógicas de ensino enciclopédico, pautado na memorização e na repetição de fórmulas prontas, pouco criativo e pouco problematizador, persistem e, até hoje, estão presentes no imaginário de boa parte da população, como sendo a própria prática educativa, no pressuposto de sua neutralidade. Apesar dos esforços da Companhia de Jesus para catequizar os índios e os pobres, sua educação foi focada na formação das elites dirigentes; este caráter elitista é outra forte raiz da educação pública brasileira.

Por conta da crise do modelo agrário-comercial-exportador e do impulso à industrialização como modelo nacional-desenvolvimentista, a década de 1920 produziu o declínio das oligarquias, tão firmemente instauradas em solo brasileiro. A classe burguesa ganhou destaque e se fortaleceu como poder econômico e expectativa social. A queda da oligarquia e a ascensão da burguesia industrial, aliadas às transformações políticoculturais emergentes, às Guerras Mundiais, à Revolução de 1930, ao Tenentismo, à presença do Partido Comunista, à Semana de Arte Moderna e às linhas de pensamento filosófico dos escolanovistas e dos católicos, serão incorporados à educação e influenciarão a organização escolar neste período.

4- Em torno das décadas de 1970 e 1980; após a ditadura de Salazar (1974) e Franco (1975), em Portugal e Espanha, respectivamente; e no Brasil (1985); além da época de ascensão do regime socialista francês (1978). 
É sempre bom lembrar que, até a década de 1930, não havia exigência de formação específica ou pré-requisitos para o exercício profissional do magistério do ensino secundário, somente alguns exames praticados por pessoas formadas em qualquer curso superior.

Apesar do movimento da Escola Nova (1932) e de perspectivas mais democráticas para a educação, ainda se tratava de uma educação pública para poucos, com restrita formação dos professores e com métodos pedagógicos bastante tradicionais, pautados numa didática instrumental e tecnicista que tinha por objetivo a transmissão de conteúdos previamente selecionados por dirigentes políticos.

Assim, nas décadas de 1950 e 1960, a rede pública de ensino estava disponível para apenas 35\% da população, atendendo, prioritariamente, a classe média das grandes cidades e a elite econômica. Essa escola já se beneficiava dos resultados de investimentos na formação de professores; talvez, por isso, a escola pública deste período seja bastante lembrada como uma escola de excelente qualidade ${ }^{5}$.

Na contramão dessa escola elitista e excludente, já se podia notar a presença crítica das raízes da Pedagogia do oprimido, de Paulo Freire (1984), no Nordeste brasileiro. Naqueles tempos, assim o autor se expressava, "é preciso des-ocultar a ordem prévia que estrutura a sociedade; é fundamental que cada sujeito aprenda a identificar seu local social, para que deste lugar apreenda a lógica de domesticação que o sistema social impõe" (p. 32, grifo do autor).

A escola pública nascente nas décadas de 1950 e 1960, de relativa qualidade pedagógica, vinha num crescente de ajustes, especialmente pelas novas exigências de formação de professores e pelos estudos e pesquisas que começavam a compreender o fenômeno educativo e que ocorriam nas então recentes universidades públicas, com destaque à Universidade de São Paulo (USP), à Universidade do Distrito Federal (UDF), que viria a se tornar a Universidade do Estado do Rio de Janeiro (UERJ), além da força nascente do Instituto Nacional de Estudos Pedagógicos (Inep), do Ministério da Educação e Cultura - atual Instituto Nacional de Estudos e Pesquisas Educacionais Anísio Teixeira -, sob a presidência de Anísio Teixeira. Em 1971, segundo o documento Análise da situação atual do Inep e proposta de reformulação de sua estrutura e objetivos, do Inep,

As funções do Instituto Nacional de Estudos Pedagógicos deverão ganhar amplitude maior, buscando tornar-se, tanto quanto possível, o centro de inspiração do magistério nacional, para a formação daquela consciência educacional comum que, mais do que qualquer outra força, deverá dirigir e orientar a escola brasileira. Os estudos do INEP deverão ajudar a eclosão desse movimento da consciência nacional indispensável à reconstrução escolar. (BRASIL, 1971, p. 10).

Este caminhar esperançoso da educação, com pesquisas e estudos sobre e para a formação docente, vai, logo a seguir, sofrer grande retrocesso, em 1964, por conta da Ditadura Militar, que acaba por esmagar e destruir o processo que gestava novas raízes à educação brasileira, quer pelo desenvolvimento de pesquisas nas universidades e centros de pesquisa, quer pelas propostas iniciais de Paulo Freire contra a educação bancária e

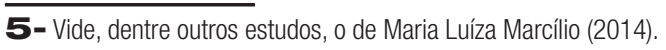


a favor de amplo processo de alfabetização de adultos. Um ponto de inflexão, tempo de desperdício da experiência; tempo de retroceder. Assim foi, de 1964 até 1985, o período da ditadura.

De 1964 a 1985, houve um aprofundamento das práticas pedagógicas tecnicistas, da didática instrumental e do ensino domesticador do pensamento. Como decorrência, vemos um empobrecimento do pensamento pedagógico e percebemos que a escola pública, os professores e os educadores vão perdendo o ethos social de pertença à sociedade, de dignidade e de compromisso. Houve uma falsa universalização da educação, uma vez que só se universalizou o espaço de entrada na escola, que por sua vez já não tinha a possibilidade de formar adequadamente seus estudantes.

No entanto, gestaram-se resistências e uma das consequências boas, talvez, tenha sido a percepção, pelos docentes, do papel político da educação. Esse sentimento concretizou-se pelos e nos movimentos políticos da didática, expressos em grande parte na virada epistemológica da didática, expressa nos livros de Vera Candau, ainda em final da ditadura, década de 1980, dentre os quais figura A didática em questão (1984). Os pesquisadores, muitos deles professores, estavam em alerta e em processo político de resistência ${ }^{6}$. Assim, quando foi possivel ler a educação brasileira de novo, pôde-se contar com novas teorias explicativas da escola pública. Desta forma, é importante focar, aqui, que as teorias crítico-reprodutivistas (TCR) foram fundamentais para a compreensão e a revisão do papel político e social da didática.

\section{Teorias crítico-reprodutivistas (TCR)}

Surgidas na França entre as décadas de 1960 e 1970, as TCR foram um grande movimento de pesquisadores que absorveram as teses reprodutivistas e passaram a pesquisar os mecanismos que permitiam à escola servir aos interesses capitalistas e produzir práticas sorrateiras, disfarçadas, que dificultavam a presença, a permanência e o desempenho das classes populares na escola (CHARLOT, 2013).

Foi grande o mérito dos estudos decorrentes dessas teorias, que deram sustentação teórica à crítica de uma pedagogia tecnicista, subserviente aos propósitos da lógica econômica. Por meio desse respaldo teórico, pode-se tensionar o mito de que a escola era a redentora da classe popular e que, através dela, a classe operária poderia ascender socialmente. 0 movimento deixou bem clara a concepção de que a escola, tal como era, servia para referendar e manter as desigualdades sociais ${ }^{7}$.

Tais estudos realçaram como as práticas utilizadas pelas escolas para produzir disciplina, respeito à hierarquia, submissão, verdades únicas, uniformização de comportamentos e posturas eram, na realidade, práticas que oprimiam, especialmente, a classe popular e que dissimulavam, sob o discurso de equanimidade, seu caráter opressor. Tudo parecia bem naturalizado e, assim, a criança de classe popular, que não possuía o mesmo capital cultural de alunos de outras classes sociais, havia que se submeter à

6- Nos anos de 1980, já estavam presentes a Associação Nacional de Educação (Ande), o Centro de Estudos Educação e Sociedade (Cedes) e a Associação Nacional de Pesquisa e Pós-Graduação em Educação (Anped), criados, respectivamente, em 1977, 1978 e 1979.

7- Para análise mais aprofundada dessas teorias, vide: Althusser (1983), Bourdieu e Passeron (1992), dentre outros. 
lógica de uma escola que era construída para a lógica da dominação, apequenando as possibilidades da classe social popular de encontrar o mesmo êxito que os alunos que já circulavam nessa mesma lógica letrada e que possuíam o capital cultural adequado às cobranças escolares.

Enfim, os mecanismos escolares perpetuadores das desigualdades que se concretizam no âmbito escolar se tornaram, através das teorias reprodutivistas, mais explícitos, esclarecendo práticas de simulação de igualdade em que vigoravam tratamentos iguais para crianças diferentes (BAUDELOT; ESTABLET, 1987). Assim, essas teorias ajudaram a produzir uma nova compreensão do papel da escola como aparelho ideológico do Estado.

Segundo Althusser (1970), pesquisador dessas teses reprodutivistas, a escola se constitui como um dos principais aparelhos ideológicos do Estado, pois funciona como regulador e controlador das massas, sendo as práticas escolares responsáveis por preparar a mão de obra para as indústrias, consumando a ideologia da alta burguesia dominante. No entanto, o autor realça que a escola não é o único Aparelho ideológico de Estado (AIE), pois há a igreja, a família, as instituições políticas e jurídicas diversas:

Todos os aparelhos ideológicos de Estado concorrem para o mesmo resultado: a reprodução das relações de produção, isto é, das relações de exploração capitalistas. Cada um deles concorre para esse resultado de uma maneira que lhe é própria, isto é, submetendo (sujeitando) os indivíduos a uma ideologia. (ALTHUSSER, 1970, p. 32).

Essas teorias foram importantes para o conhecimento dos mecanismos que configuram a dinâmica social das escolas; no entanto, tais teorias também produziram um certo pessimismo em relação à escola, pois não consideraram o movimento dialético no interior dos espaços escolares, propondo um olhar assaz funcionalista em sua compreensão.

0 tempo mostrou que é preciso relativizar a influência dos mecanismos de repressão desencadeados pelos AIE. Se estudos demostraram essa perspectiva, também outros estudos decorrentes mostram que nem tudo ocorre em direção única. Há sempre reações e resistências. 0 estudo de Charlot $(1997,2005)$ sobre o fracasso escolar e as relações dos alunos com o saber indica que há outros mecanismos que podem explicar as dificuldades da classe popular para obter êxito nas práticas educativas ali desenvolvidas.

É importante realçar que tais teorias desconsideraram os conflitos no interior do espaço escolar, as perenes contradições que nele emergem, e deixaram de lançar luz sobre as resistências que, necessariamente, surgem nos espaços-vida da dinâmica escolar. No entanto, permitiram conhecer os mecanismos que ocultam a inculcação ideológica, bem como os avanços nos estudos culturais, especialmente os estudos na área de currículo ${ }^{8}$. Portanto, as teses reprodutivistas, ao mesmo tempo em que produziram fissuras nas subjetividades a respeito do papel redentor da escola, trouxeram outras interpretações à teoria crítica, demonstrando a possibilidade real do uso da escola como aparelho regulador do Estado, exprimindo bem o conceito de Chauí (2016) sobre uma ideologia mascarada, disfarçada. Assim, foi possivel que se compreendesse melhor o fenômeno de dominação

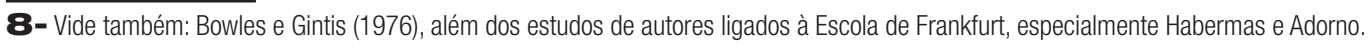


cultural, bem analisado por Adorno (sobretudo ao discorrer sobre a ideologização do capital cultural), e estas compreensões propiciaram novos estudos da pedagogia crítica, até, ouso dizer, novas compreensões da própria teoria freiriana.

\section{A escola desterritorializada}

Entre crises e tensões, a escola pública começa a ser reinterpretada. Observa-se uma perda e transfiguração do sentido que a classe média e a elite passaram a atribuir a esse espaço público de formação. A falta de investimento nas escolas; a precária formação de docentes que ocorreu, especialmente, no período da Ditadura de 1964; e os movimentos reivindicativos de professores, sob forma de greve, que se fizeram necessários para tentar conseguir melhores condições de trabalho na escola pública, impactaram sua valorização social. Gradativamente, percebe-se menor adesão ao projeto de escola pública e sucessiva transferência de alunos da escola pública às escolas particulares, sob a compreensão equivocada de que ali se faria uma formação melhor. Para compreender melhor, "das 27 milhões e 500 mil crianças matriculadas em escolas de $1^{\circ}$ grau de todo o país (1989), 87,5\% cursavam escolas públicas gratuitas, mantidas com a receita de impostos" (GOLDEMBERG, 1993, p. 3). Há que se investir sempre nas escolas públicas, laicas e gratuitas para todos. 0 que ocorreu, de forma bem significativa, foi a perda de poder e de significado da importância da escola pública. Há pouca visibilidade de sua importância; sua voz é pouco reconhecida; sua causa, desvalorizada.

Dados do Censo de 2018 mostram que a rede pública no Brasil é ainda muito grande e que $77 \%$ dos alunos do ensino fundamental estão na escola pública. Porém, a escola pública está, aos poucos, se configurando como uma escola para pobres, como bem explicita Libâneo (2012, p. 19):

[...] a escola que sobrou para os pobres, caracterizada por suas missões assistencial e acolhedora (incluídas na expressão educação inclusiva), transforma-se em uma caricatura de inclusão social. As políticas de universalização do acesso acabam em prejuízo da qualidade do ensino, pois, enquanto se apregoam índices de acesso à escola, agravam-se as desigualdades sociais do acesso ao saber, inclusive dentro da escola, devido ao impacto dos fatores intraescolares na aprendizagem.

A escola que sobrou está sem voz, sem representatividade, transformou-se em um espaço somente de transmissão de pobres informações. Um espaço sem vida, sem condições de ser emancipatório, especialmente para os menos favorecidos culturalmente. É preciso ser realista para dizer que a didática, sozinha, não terá forças para transformar essa escola e que a escola, por sua vez, não vai ter forças para, sozinha, mudar a sociedade.

Será preciso que o coletivo de educadores, focados na possibilidade de tornar a práxis docente revolucionária, do ponto de vista epistemológico e político, atue de forma "radical, rigorosa e de conjunto" 9 . Por isso, neste texto, quero trazer resultados de pesquisa em que são reveladas algumas análises sobre condições de formação docente que precisam

9- Como se refere Saviani (1996, p. 20) sobre a necessária reflexão filosófica. 
ser incorporadas nos processos formativos, na perspectiva de um pensamento novo sobre o fenômeno de ensinar de modo crítico e decolonizador.

É preciso, de alguma forma, salvar a escola da fúria do capitalismo, pois, como escreve Rolnik (2019, p. 4), “o capitalismo está conseguindo colonizar o conjunto do planeta”, para, a seguir realçar que, neste regime, já não conseguimos nos reconhecer em nossa experiência coletiva como sujeitos. A psicanalista alerta-nos de que essa situação formata e coloniza nossos desejos de forma que nem sempre nos apercebemos do quanto estamos sendo oprimidos por uma lógica de colonização que obstrui nossas perspectivas de futuro. A pesquisa que trago neste texto carrega dados que parecem confirmar que nossas escolas estão colonizadas por discursos e poderes alheios à sua dimensão epistemológica.

Desta maneira, trago como perspectiva a proposta de decolonização da didática, na mesma direção que Ballestrin (2013, p. 105) afirma sobre a necessidade de "um outro pensamento; quiçá uma nova teoria, ou uma outra episteme", que alavanque um "giro decolonial". Persigo esse giro para potencializar as possibilidades da didática de conduzir e fundamentar as práticas docentes nestes tempos adversos.

Posso afirmar que, em minhas aproximações aos sentimentos e pensamentos do professor de escola pública do ensino fundamental, pude perceber que o sujeito nem sempre se percebe enredado em uma lógica produtivista, superficial, colonizada. Identifiquei muitas falas que podem ser resumidas da seguinte maneira: "É bom mesmo que eu receba um roteiro do que devo dar em sala de aula, assim não preciso gastar tempo pensando!". Sem muita reflexão, mas convictas, muitas professoras afırmam: "Assim (com roteiro) fica mais fácil passar aula!”.

\section{Metodologia da pesquisa: do bilan de savoir à escuta coletiva crítica}

Considerando estudos anteriores sobre a necessária participação dos sujeitos, quer na coleta de dados, quer na interpretação deles (FRANCO, 2005, 2012), considerando as possibilidades de falácias de participação dos sujeitos (STRECK, 2017) e estudos recentes que alertam para o lugar de fala (RIBEIR0, 2019), eu estava bastante preocupada em captar os verdadeiros sentimentos e as concepções dos professores em relação à didática e compreender como percebiam as possibilidades e presenças da didática em seus espaços de docência na escola pública.

Dentre as possibilidades metodológicas colaborativas para tal momento investigativo, julguei que o ideal seria a utilização do bilan de savoir como método de coletar dados, que permite obter respostas sem emitir perguntas. Isso porque, segundo Charlot (1999), quem pergunta sempre induz a determinação do campo da resposta, mesmo sem perceber.

0 bilan de savoir, como instrumento metodológico, busca criar uma atmosfera na qual o entrevistado tenta declarar o que sente e pensa; no entanto, estando no próprio ambiente da escola, o sentir e o pensar podem ser expressos para atender à expectativa que ele presume ser a da escola (CHARLOT; BAUTIER; ROCHEX, 1992).

É preciso muito cuidado, uma vez que, segundo os autores, trata-se, sempre, de um discurso em situação. Desta forma, é preciso evitar induzir o campo de pertinência da resposta, o que provocaria um grave viés quando o pesquisador se interessa pelo sentido 
conferido pelo pesquisado (CHARLOT; BAUTIER; ROCHEX, 1992). Os autores realçam que não se pode, por exemplo, induzir que a escola deva servir para alguma coisa se o objetivo da coleta de dados é saber qual sentido a pessoa confere à escola.

Uma das grandes questões no bilan de savoir é identificar uma pergunta, ou um roteiro de perguntas, que produza uma reflexão no sujeito para além das respostas prontas que este normalmente teria. Como afirma Kalali (2007, p. 18, tradução nossa), "Da ótica dos sujeitos, a relação com o saber se assemelha a um processo de autoformação, revelador da subjetividade e da reflexividade o indivíduo".

Considerando o cuidado com a pergunta a ser feita, o método se torna participativo e mobilizador dos mecanismos de busca de sentido. Desta forma, após várias reflexões e interlocuções, defini a seguinte questão inicial para ser perguntada aos professores: quando eu leio ou ouço a palavra "didática”, ou coisas ligadas à didática, minha reação é pensar que...

Desta forma, supõe-se que o entrevistado possa dar uma resposta menos programada do que, por exemplo, se lhe fosse perguntado algo como: qual a importância da didática para sua prática? Porque, neste caso, eu (pesquisadora) estaria já pressupondo uma importância do fenômeno didático; além disso, o professor poderia lançar mão de respostas previamente elaboradas por discursos alheios.

Em um primeiro momento, os docentes escreveram narrativas a partir da questão posta acima. Depois de analisadas e compreendidas como sentidos latentes à questão, no caso, da didática, foi possível estruturar eixos de significados que serviram de guias para entrevistas não estruturadas, bem abertas, aproximando-se de uma escuta pedagógica. Os sentidos foram se refinando e se evidenciando. Analisados coletivamente sob a perspectiva da hermenêutica crítica, deram o fio norteador dos sentidos expressos no processo de compreensão do significado que os docentes atribuem à didática.

Após o filtro da primeira questão - Quando eu leio ou ouço a palavra “didática”, ou coisas ligadas à didática, minha reação é pensar que... -, outras emergiram e corresponderam à segunda fase: 1) Quando olho em volta de meu espaço de trabalho na escola pública, eu percebo a presença da didática...; 2) Em minha vida profissional de docente, sinto que a didática pode me ajudar em... pode me ajudar com...; e 3) Eu penso que ensinar é...

Observe-se que a questão é uma afırmação aberta, numa folha em branco, para que os sujeitos possam exprimir falas que desejarem, narrativas próprias.

É preciso alertar que o bilan de savoir é um processo crítico-dialético que vai se estruturando sob forma de falas expressivas que se cruzam e se complementam. Afirma Charlot (2001, p. 92, tradução nossa) que "a relação com o saber se exprime sob forma de um discurso, pela formulação e não por um contra ou a favor, como numa votação [...] um bom bilan de savoir é difícil de fazer, porque ele supõe uma boa relação com o saber".

Trabalhei com seis pesquisadores auxiliares, que realizaram a coleta de dados em: Rio de Janeiro, Duque de Caxias, São Paulo, Santos, Aparecida do Norte, Registro e Juazeiro do Norte $^{10}$. Ao todo foram 150 pessoas entrevistadas a partir das questões norteadoras de significado, previamente elaboradas, conforme o parágrafo anterior. A análise dos dados coletados foi realizada por mim e por três dos pesquisadores.

10- Cidades do Rio de Janeiro, do interior de São Paulo, do Vale do Ribeira, da Baixada Santista, de Fortaleza e do Nordeste brasileiro. 
Após a coleta e a análise dos dados, foram realizadas conversas dialogais de escuta crítica com três professores de escolas públicas, um de Santos e dois de Campinas. Além disso, realizei um passeio pedagógico por uma escola pública, acompanhada por uma professora já aposentada que lecionou na referida escola e uma professora iniciante.

Todos os dados foram analisados na perspectiva da hermenêutica crítica, conforme Thouard (2002) e Franco (2012).

\section{Dados empíricos}

Para este texto, vou elencar apenas alguns dados básicos que considero fundamentais para elaborar a análise construtiva de alguns conhecimentos em relação à didática.

0 trabalho de transformação dos dados empíricos em dados concretos é longo e necessita de muita interlocução, seja com a teoria, seja com os sujeitos da prática.

Tentei, sempre que possível, chamar os participantes da pesquisa e outros sujeitos do mesmo lugar social e/ou profissional dos sujeitos da pesquisa para estranharem e reconhecerem os dados, na direção da construção de conhecimento: olhar os dados; escutar as circunstâncias e os contextos; tentar compreender e buscar interpretar para, então, puxar e tecer fios de compreensão coletiva e, assim, gerar uma aproximação com a criação do conhecimento.

A partir da questão, quando eu leio ou ouço a palavra “didática”, ou coisas ligadas à didática, minha reação é pensar que... pudemos identificar que as respostas se vinculavam à percepção do ato de ensinar, que prefiro denominar fenômeno do ensino. As respostas mais frequentes giraram em torno do eixo "didática e ensinar":

1) Penso nas possibilidades de ensinar

2) Sempre vejo um professor ensinando

3) Didática, para mim, me conduz a pensar em métodos de ensinar

4) Penso em maneiras de ensinar

5) Penso numa força a conduzir o ensino

6) Penso em formas tradicionais de ensino

7) Sempre a ligo a técnicas de ensinar

8) Penso nas disciplinas, em ensinar conteúdos

9) Conduzir a aula

10) Método e técnica de ensino

11) Aplicar métodos

12) Recursos para o ensino

13) Sistematização do ensino

14) Transmitir conhecimento

15) Como fazer para ensinar.

Poucos professores fizeram menção à aprendizagem dos alunos, dando até a impressão de que compreendem que o processo de ensino está desvinculado da aprendizagem; tive a impressão de que muitas falas consideram mesmo que ensinar independe de aprender. 
Aqueles que se lembraram da aprendizagem o fizeram, em sua maioria, de uma forma bem instrumental, bancária e estratégica:

1) Facilitar (ajudar) a aprendizagem do aluno (3)

2) Passar o conhecimento para o aluno (6)

3) Repasse de conteúdo (5)

4) Conquistar a atenção do aluno (4)

5) Fazer o aluno prestar atenção (3)

Há diversos estudos, como o de Franco (2008), Franco e Guarnieri (2011), Libâneo (2008), Pimenta, Franco e Libâneo (2010), mostrando que a didática está ausente dos processos formativos de futuros professores, e isso pode ser percebido em algumas respostas, que classifiquei como sentidos de uma didática em desuso:

1) Conceito em desuso (hoje substituído por metodologias e projetos) (1)

2) Conceito usado antigamente na escola tradicional (2)

3) Palavra antiga, hoje se fala construtivismo (1)

4) Sala de aula do antigo magistério (2)

5) Ensino antigo (2)

Considero bem interessante esta submissão do conceito de didática ao conceito de metodologia para futuros estudos e pesquisas: a tomada da parte pelo todo; seria um sinal do neotecnicismo na educação, impactado pelas políticas neoliberais de formação, dominando já a subjetividade dos docentes? Parece que sim, uma vez que pude perceber, durante a visita a uma escola pública, no diálogo com duas docentes - uma recém-aposentada e a outra que iniciou há 5 anos sua docência -, que, quanto mais iniciante é o professor, mais ele acredita na necessidade de roteirização da prática. A jovem professora considera que é preciso aprender o modo certo de fazer a aula, fala da importância de existirem roteiros que orientem o fazer; no entanto, a antiga mestra pensa de outro modo, e verbaliza: aos poucos vamos aprendendo a pensar na prática, com a prática! Tudo pode ajudar, no entanto, se eu não tiver segurança pedagógica, nada faz sentido, nenhuma orientação técnica funciona!

Nesta pesquisa, no entanto, pude perceber que há um grupo desses professores jovens, em torno de 10\%, que acredita e valoriza o conceito do professor que reflete. E assim respondem em relação ao sentido que atribuem à palavra didática:

1) Reflexão sobre o fazer

2) Formação contínua

3) Ensinar com qualidade

4) Ideologia para ensinar

5) Postura para ensinar

6) Ética para ensinar

7) Direção de sentido 
Esses dados talvez sejam indícios de novos olhares e de novos componentes nas subjetividades que conduzem as práticas profissionais. Mas também podem ser apenas discursos pouco internalizados que não conseguem se concretizar em novas práticas. Porém, se funcionarem como contrapontos reflexivos, já serão importantes para a dinâmica dialética de reconstrução de um conceito.

No entanto, novas contradições surgem. Ao serem perguntados sobre onde percebiam a presença da didática na escola em que trabalhavam, veio à tona, de forma muito forte, a concepção de organização. Os docentes afırmaram que percebem a presença da didática na escola nos momentos de fazer o planejamento; de organizar exposições, feiras e festas; na organização do mural informativo; na organização de material de infraestrutura; e também na organização do recreio e das atividades lúdicas.

Os professores consideram que a organização de materiais e eventos é uma atividade que demonstra didática. Por que essa resposta? Aprofundando o debate, dizem que não há didática sem atividade de organização e sequenciamento de conteúdos. Os professores percebem a presença da didática nos parâmetros curriculares e nos projetos que surgem dos órgãos superiores para serem aplicados e nos livros didáticos.

Além disso, os professores realçaram que querem a didática. Querem porque precisam dela e precisam para poder vislumbrar uma aula que produza efeito. 0 que seria uma aula assim? Os professores entrevistados respondem: uma aula na qual os alunos prestem atenção e aprendam. Aprofundando um pouco a reflexão, perguntei: e como sabem que os alunos aprenderam? É fácil, respondem: é quando eles sabem responder às questões do livro, do texto ou as que sugerimos. Ou seja, é sinal de que os alunos aprenderam quando dão as respostas certas e não fazem bagunça, ou ainda quando fazem com vontade, dizem os professores.

Os professores querem que a didática lhes ensine técnicas para disciplinar os alunos; para fazê-los copiar a tarefa da lousa ou do livro; para responderem as questões da lição. Para isso, imaginam que a didática pode oferecer regras de sequenciamento de conteúdos; etapas para dividir a aula em tempos de ouvir e tempo de fazer; ajudá-los na organização de uma aula com começo, meio e fim. Consideram que não aprenderam, em seus cursos de licenciatura, a dar uma aula. Até aprenderam a planejar, mas não conseguem dar a aula planejada. Os alunos não ficam quietos, e isso, segundo eles, atrapalha a programação.

Desejam que a didática adormeça os alunos; que retire da sala as contradições entre o pensar e o fazer; desejam que haja um ambiente de recepção da aula por parte dos alunos, pois só assim, dizem, conseguirão transmitir tudo que precisa ser transmitido. Infelizmente, esse é o verbo que ouvi com muita frequência entre os docentes: transmitir a aula; transmitir conteúdos; transmitir modos de pensar.

Quando alguns consideram que precisam refletir, muitas vezes desejam refletir sobre a melhor forma de transmitir. Também por isso desejam que a didática lhes proporcione estratégias para driblar esses inconvenientes da sala de aula, ou seja, alunos que não prestam atenção; que não param; que não fazem as lições.

Desejam muito que a didática lhes ensine a rever a prática; a completar sua formação; a refletir nos problemas; a saber selecionar conteúdos. 
Acreditam que a didática pode salvar a escola sem infraestrutura; recompor a equipe pedagógica; superar as dificuldades de uma sala com muitos alunos; superar uma formação pedagógica incipiente.

Considero que há algo de mágico, ou de ingênuo, nesse pensamento. No entanto, quando insisti para que os professores indicassem sugestões para a didática, percebi uma criticidade maior. Colocam que não percebem clareza na concepção de métodos de ensino tal qual existem nos textos didáticos que leem ou mesmo nos livros que já leram. Consideram que a didática poderia lhes oferecer teorias e princípios para melhor compreender os alunos, os contextos sociais e cognitivos. E mais do que isso: como trabalhar com contextos diferentes numa mesma sala de aula, como articular e partilhar sentidos de vida e de mundo.

Solicitam que a didática responda às suas questões pedagógicas: como criar sentido e desejo de aprender nos alunos? Como trabalhar a verdadeira formação dos alunos para além da pressão das avaliações externas? Como o professor pode atribuir sentido às próprias práticas docentes? Como pode a didática ajudar o professor a organizar os pensamentos? A identificar as bases pedagógicas de seus trabalhos? Perguntam: que respostas a didática pode nos oferecer?

\section{Observando o espaço escolar: onde está a didática?}

Entrei em duas escolas acompanhada por duas professoras: uma na ativa e outra que acabara de se aposentar. Queria reconhecer a escola pública de hoje através dos olhos das professoras. Tentava estranhar e redescobrir a escola de hoje, diferente daquela em que fui diretora décadas atrás.

Notei o esforço de organização do espaço, um aspecto valorizado por ambas. Elas me mostraram os quadros de aviso e as paredes sujas, algumas pichações, alguns desenhos e muitas paredes descascadas. Mas nada de assustar, apenas falta de uma manutenção contínua. Afinal, são escolas localizadas em bairros de trabalhadores. Notei também o esforço para disciplinarização na escola: recados, avisos, alguns inspetores e serventes em muita ação.

À direção em sala fechada, nem me apresentei: era final de ano, e o trabalho era imenso. Conversei com alguns professores, estavam em época de provas. Não dizem época de avaliação, mas de provas.

Em todas as salas havia lousas negras, apagadores desgastados e giz branco.

Há horários por toda a escola sinalizando aulas e salas, entradas e saídas, ritos, e há livros de presença. Atmosfera similar foi exposta por Candau (2016, p. 351-352) com precisão:

[...] “adequação às normas hegemônicas e monoculturais do “certo, correto, aceitável e bom””; sala de aula, em geral com a mesma disposição (alunos enfileirados, quadro negro/verde/branco na frente etc.); seriação-hierarquização das disciplinas escolares; em geral painéis a serviço da organização, e da gestão da escola; pouca participação dos alunos na construção dos painéis e na decoração da escola. 
Na sala de professores, na hora de um intervalo, percebi um clima de trabalho, cansaço e uma certa descrença na escola pública. Pensamentos expressos em falas como: Isso não tem jeito! Ninguém se interessa pela escola pública! Aqui só circula a classe social que não pode pagar.

Não encontrei risos, sinais de alegria, nem atividades lúdicas. Tudo parecia sem graça e muito sério. Pude escrever: "aridez de espaço físico, nada agradável”.

Aproveitando um grupo de professores na sala que lhes é destinada, perguntei: para que serve a didática? A resposta quase unânime foi: para melhorar o ensino! Se é para melhorar o ensino, o que seria então o ensino? Encontrei respostas variadas em torno de transmissão de conhecimentos, transmissão de conteúdos, transmissão de saberes e organização da aula.

Perguntei, a seguir: "se você organizar bem sua aula, o ensino será bom?” Alguns responderam: "depende dos alunos deixarem a aula ser exposta; se os alunos ficarem quietos eu posso expor sem problemas e a aula será boa”.

Fiquei com a impressão de que o sentimento é o de que os alunos atrapalham a aula, de que uma aula sem alunos seria adequada. Conversei com eles sobre isso e responderam que sem disciplina é impossível uma aula ser boa.

\section{Uma contradição interna: a didática como teoria do ensino? A didática como teoria da formação?}

A grande questão que veio à tona foi a de pensar uma nova pesquisa: Como a teoria didática, trabalhada nos cursos de formação de professores, tem interpretado a natureza do fenômeno ensino? Como as práticas institucionais têm produzido o sentido de ensinar? Como as políticas públicas de avaliação têm considerado o fenômeno do ensino?

Acredito que nossas escolas dependem de como o processo de ensino é interpretado, tanto nas subjetividades dos atores sociais quanto nas políticas públicas, e, mais ainda, nas práticas institucionais escolares.

Kincheloe (1996) analisa que o conhecimento pode ser construído nos alunos se, e somente se, a informação das disciplinas interseccionar com os entendimentos e as experiências que os indivíduos carregam com eles para a escola. Assim, o autor considera fundamental que o professor contemporâneo seja formado de modo a saber ajudar os alunos a reinterpretarem suas próprias vidas e descobrirem novos talentos como resultado de seu encontro com o conhecimento escolar.

Essa concepção de cognição como um processo de conhecimento pressagia uma mudança pedagógica profunda. Será preciso que a didática navegue por essa perspectiva de modo a superar a trivialização da aprendizagem nos processos escolares. É preciso urgentemente superar a concepção de transmissão de informação ou mesmo conhecimento quando falamos em processo de ensino.

Desde Paulo Freire e da origem da Pedagogia do oprimido, há um consenso pedagógico em torno da educação não bancária, não apenas transmissiva, não domesticadora do sujeito que aprende. Mas há ainda, no mundo atual, uma forte compreensão de que o ensinar seja transmitir algo para uma cabeça vazia, para um sujeito a-histórico. 
A didática, como teoria de ensino, precisa continuar insistindo na compreensão de que não há ensino fora do sujeito que interpreta. Nesta perspectiva, todo ensino será sempre um processo formativo, que induz à autoformação, que reinterpreta convicções e atualiza concepções de mundo.

\section{Didática e o ensino: contradições}

Por meio de duplas triangulações nas categorias de análise foi possível vislumbrar ao menos cinco contradições internas que perpassam historicamente a concepção de didática:

1. A contradição pedagógica: uma teoria de ensino ou uma teoria da formação?

2. A contradição ontológica: ensino requer relações verticais ou participativas?

3. A contradição prática: didática que quer ensinar versus didática que não pode ensinar.

4. A contradição epistêmica: o aluno não quer aprender; o professor não pode ensinar; o professor quer ensinar, o aluno não consegue aprender.

5. Contradição conceitual: o professor que ensina? 0 aluno que aprende? Aprendendo-se/ensinando-se.

6. Contradição ética: enquanto ensino, do meu jeito, do meu modo, excluo gentes; excluo alunos.

Essas contradições não poderão ser explicitadas no âmbito deste artigo, no entanto, quero realçar a importância da identificação dessas contradições, de forma a permitir dar um passo a mais na compreensão da teoria e da prática didática.

0 sentido de contradição que aqui expresso vincula-se ao pensamento de Mao Tsé-Tung (2008) ${ }^{11}$, que alerta que a contradição fundamental no processo de desenvolvimento de algo está sempre em caminho:

A contradição fundamental no processo de desenvolvimento de uma coisa e a essência do processo determinado por essa contradição fundamental não desaparecerão até que o processo esteja completo; mas, num processo longo, as condições em geral se diferenciam a cada etapa. [...] A contradição fundamental torna-se cada vez mais intensificada enquanto passa de um estágio a outro no processo prolongado se as pessoas não prestam atenção aos estágios no processo de desenvolvimento de uma coisa não podem lidar corretamente com suas contradições. (TSÉ-TUNG, 2008, p. 101).

Esse alerta sinaliza para olharmos a história do conceito desde Comenius, e compreender as questões que nos afetam hoje, especialmente as condições de predominância da lógica capitalista impregnando e deformando as práticas educativas e os sentidos postos à dimensão de ensinar, lógica que despersonaliza a figura do professor, retira o sentido das práticas escolares e precariza a formação dos docentes.

11- Reescrito por Zizek (apudTSÉ-TUNG, 2008). 
0 mercado comanda a prática escolar, os sentidos da escola, a profissionalização docente. 0 resultado é este que temos visto: escolas sem sentido, práticas escolares esvaziadas de artesanias educacionais e lotadas de materiais que produzem lucros fora dos sujeitos da educação. Neste clima, avesso à natureza da educação e do ensino, as contradições se agigantam e giram em torno de si, deixando de fluir para sua superação epistemológica.

Pude identificar a contradição exposta em professores com boa vontade, que querem e gostam de ensinar. Muitos deles, munidos da melhor boa vontade, desejam roteiros bem específicos para conduzir suas aulas; desejam que a escola tenha instrumentos de controle dos comportamentos dos alunos; desejam a ordem e a passividade; gostariam de treinar os alunos nas respostas certas; coíbem inovações e perguntas impertinentes; almejam uma didática que os autorize a ser autoritários, a se utilizarem de relações verticais de mando e obediência e, quando querem ousar, de metodologias ativas, que treinam respostas prontas e incentivam a memorização.

\section{A urgência para uma didática decolonial}

Os dados da pesquisa me conduziram a refletir a partir de alguns equívocos e contradições que parecem permear a prática pedagógica da docência. Entre esses, gostaria de realçar algo que parece estar entranhado na concepção tradicional de didática e que permanece reificando práticas e inviabilizando mudanças. Percebi que a prática didática de muitos professores é construída sem a necessária articulação entre o eu epistêmico e o eu empírico. 0 eu empírico prevalece sempre e isso talvez explique o desejo dos docentes por modelos, roteiros, receitas e estratégias de ensino. Os alunos não são percebidos em suas especificidades epistêmicas; assim, esses professores acreditam que a simples apresentação das informações e dos conteúdos põe a inteligência do aluno em movimento.

Mas isso não é verdade. Funciona para aqueles que já possuem relações produtivas com o saber, no entanto, eles são poucos: há muitas colonizações e subjetivações no eu epistêmico. 0 capital cultural trazido pelos alunos de diferentes origens sociais difere muito; as relações com o saber escolar são sempre múltiplas e diversas, conforme já nos esclareceu Charlot (2005). Assim, todo processo de ensino será sempre um processo de inclusão, o que requer uma didática crítica e intercultural. Reafirma Charlot (2005, p. 43): "o eu epistêmico, isto é, o sujeito como puro sujeito de saber, distinto do eu empírico, não é dado; ele é construído e conquistado”.

Ora, essa conquista é tarefa didática. Reforça Charlot (2005, p. 44): "De fato, a constituição do eu epistêmico não é somente uma condição da situação didática, é também um de seus efeitos [...]”. Quem é o sujeito da aprendizagem? Que histórias e contextos traz para a escola? E, usando o conceito de Ribeiro (2019), ouso perguntar: qual é seu lugar de fala? Como o professor articula os diferentes lugares de fala presentes numa mesma sala de aula? Como estabelecer a prática dialogal se não compreendermos os diferentes lugares de falas?

Sabemos que a didática tradicional, instrumental, partiu do pressuposto de que já existe, por princípio, um eu epistêmico favorável à aprendizagem. Portanto, dentro desta lógica, basta apresentar bons materiais e métodos, ou seja, condições didáticas externas 
para que a aprendizagem se realize. Insistir nessa perspectiva é perpetuar o elitismo da educação. É pensar numa escola para aqueles que já são culturalmente beneficiados.

Historicamente, a didática buscou a suposta fala hegemônica da modernidade. Como alerta Mignolo (2005, p. 75), "a colonialidade é constitutiva da modernidade, e não derivada”. Assim, para que a didática funcione como prática inclusiva e emancipatória, será preciso decolonizá-la. Será preciso buscar uma nova epistemologia didática, que decorra de um pensamento pedagógico outro e produza práticas pedagógicas outras.

Realço que assumir uma nova epistemologia didática implica, sobretudo, adotar outro pensar/fazer pedagógico. Conforme afirma Ballestrin (2013, p. 105, grifo nosso): “'Pensamento outro” - quiçá uma “teoria outra' ou 'episteme outra”. Esse "giro decolonial" se constitui como um "movimento de resistência teórico e prático, político e epistemológico, à lógica da modernidade/colonialidade” (BALLESTRIN, 2013, p. 105, grifo nosso).

Essas análises carecem de um olhar profundo à didática e indicam: a necessária e fundamental presença da didática nos processos de formação, uma didática crítica, intercultural, multidimensional e focada em uma nova forma de considerar o ensino: decolonizada e crítica; a necessidade de estudos e pesquisas avançados na/da didática com foco na compreensão das contradições que permeiam a natureza do fenômeno ensino, tais como o de Cruz (2017), no qual a autora manifesta a necessidade de um ensino centrado na escola pública, na educação básica e no trabalho docente; pesquisas avançadas que tragam novas concepções aos significados, processos e práticas do processo de ensino, considerando o fenômeno do ensino e suas peculiaridades, focando a prática de ensinar o ensino, de ressignificar o ensino - o que significa a inclusão do sujeito nos processos de interpretação das práticas; a busca de metodologias de pesquisa que incluam o conhecimento do outro da educação, do eu epistêmico do aluno, das articulações desse eu com o eu empírico; pesquisas colaborativas que tragam o olhar dos práticos em articulação com os pressupostos dos pesquisadores; e a proposta de um giro decolonial à didática, num esforço de desprender-se de seus ranços modernistas/positivistas, na perspectiva já posta por Candau (2016), que tem reivindicado a presença das relações interculturais, críticas e democráticas na certeza de uma didática decolonial.

\section{Considerações finais: reafirmando princípios fundamentais}

Nesta pesquisa, busquei encontrar respostas à questão: Qual a didática para a escola básica, pública, em tempos tão adversos? Neste processo investigativo, minhas reflexões focaram alguns princípios por meio dos quais interpretei e construí algumas compreensões à questão posta.

Em primeiro lugar, o princípio de que a escola pública é uma condição para o exercício e a vivência dos ideais democráticos e universais. Como tal, deve ser considerada como um direito de todos, como estruturante das relações sociais e políticas e um espaçotempo de vivência plural, para além e aquém das desigualdades sociais, culturais e éticas; um lugar de reconhecer, cuidar, apropriar-se do patrimônio cultural de nossos ancestrais. Assim, realço: é a ideia de escola, o conceito de escola, que precisa ser restaurado, de forma a dar condições para a ressignificação da didática.

Que ideia seria essa? A concepção de um espaço público, laico, gratuito e de convivência plural; espaço de formação de possibilidades, acessível a todos e com todas 
as condições de garantias de construção cooperativa do saber produzido, em múltiplas leituras e interpretações, permitindo que cada sujeito se aproprie de suas concepções de mundo em articulação com seu grupo social e com o momento presente. Uma escola que atinja os objetivos de instrução e de formação para todos. Uma escola que alfabetize para as letras, para os números, para as atitudes sociais e coletivas, para as emoções, para a convivência solidária e coletiva e para a sustentabilidade.

Outro princípio fundamental: a educação não pode ser concebida, tratada, compreendida pela lógica do mercado. Educação é direito e não mercadoria. Como direito, deve ser pública, laica e obrigatória. Como dever, carece incluir a todos e ofertar mecanismos, processos e agenciamentos para que todos tenham no espaço escolar as condições de bem viver e de bem desenvolver seu direito à cidadania.

A escola deve articular-se para a organização de um projeto educativo, com práticas pedagógicas que permitam a emancipação dos sujeitos, desmascarando projetos de dominação cultural que, travestidos de naturalidade e neutralidade, impedem a plena vivência dos direitos fundamentais e produzem uma leitura única do mundo. Os diferentes lugares de fala precisam estar presentes, renovando e recriando subjetividades coletivas.

Os conhecimentos trabalhados/construídos na escola precisam impregnar-se das marcas pessoais dos sujeitos. Para isso, as práticas pedagógicas precisam transmudar-se em processos de conscientização/problematização e de autonomia intelectual. É preciso que os princípios pedagógicos freirianos adentrem a práxis escolar.

Mais um princípio: a pedagogia e a didática não podem estar a serviço da exclusão, mas de projetos e práticas sustentáveis, solidárias, emancipatórias, que desenvolvam consciência dos direitos e deveres, do lugar social de cada um, da necessária premência da vida coletiva.

Nesse sentido, proponho uma luta pedagógica de resistência por meio da pedagogia crítica, insistindo em espaços para a emergência de cada sujeito nas práticas pedagógicas, evitando sua subjugação na torrente da homogeneização e padronização de modelos e formas de ensinar e pensar; a busca de práticas pedagógicas que atuem a favor do esclarecimento, da criatividade e da convivência entre sujeitos; práticas problematizadoras que induzam à pesquisa e à investigação do cotidiano, incentivando os processos de pensamento, autonomia intelectual e de reflexão coletiva.

Compatível a esta proposta pedagógica, a didática precisará desocultar sua herança domesticadora, tecnicista e buscar fundamentos e práticas decoloniais.

Reafirmo a necessidade de um giro decolonial que produza o conhecimento do outro da educação, do eu epistêmico do aluno e das articulações desse eu com o eu empírico.

Assim, reitero o princípio de que a didática tenha presença maciça na formação de futuros docentes. Uma presença que produza um mergulho renovado nos significados.

\section{Referências}

ALTHUSSER, Louis. Aparelhos ideológicos de Estado. Rio de Janeiro: Graal, 1983.

ALTHUSSER, Louis. Ideologia e aparelhos ideológicos de Estado. Lisboa: Presença 1970. 
BALLESTRIN, Luciana. América Latina e o giro decolonial. Revista Brasileira de Ciência Política, Brasília, DF, n. 11, p. 89-117, 2013.

BAUDELOT, Christian; ESTABLET, Roger. La escuela capitalista. 10. ed. Ciudad de México: Siglo XXI, 1987. BOURDIEU, Pierre; PASSERON, Jean-Claude. A reprodução: elementos para uma teoria de ensino. Rio de Janeiro: Francisco Alves, 1992.

BOWLES, Samuel; GINTIS, Hebert. Schooling in capitalist America. New York: Routledge \& Kegan Paul, 1976.

BRASIL. Ministério da Educação e Cultura. Instituto Nacional de Estudos Pedagógicos. Análise da situação atual do INEP e proposta de reformulação de sua estrutura e objetivos. Rio de Janeiro: MEC: INEP, 1971.

CANDAU, Vera Maria (org.). A didática em questão. Petrópolis: Vozes, 1984.

CANDAU, Vera Maria. Cotidiano escolar e práticas interculturais. Cadernos de Pesquisa, São Paulo, v. 46, n. 161, p. 802-820, 2016.

CHARLOT, Bernard. Da relação com o saber às práticas educativas. São Paulo: Cortez, 2013.

CHARLOT, Bernard. Du rapport au savoir: éléments pour une théorie. Paris: Anthropos, 1997.

CHARLOT, Bernard. Le rapport au savoir en milieu populaire: une recherche dans les lycées professionnels de banlieue. Paris: Anthropos, 1999.

CHARLOT, Bernard. Les jeunes et le savoir perspectives internationales. Paris: Anthropos, 2001.

CHARLOT, Bernard. Relação com o saber, formação de professores e globalização: questões para educação hoje. Porto Alegre: Artmed, 2005.

CHARLOT, Bernard; BAUTIER, Élisabeth; ROCHEX, Jean-Yves. École et savoir dans le Banlieues... et ailleurs. Paris: Armand Colin, 1992.

CHAUÍ, Marilena de Souza. Ideologia e educação. Educação e Pesquisa, São Paulo, v. 42, n. 1, p. 245-257, 2016.

CRUZ, Giseli Barreto da. Ensino de didática e aprendizagem da docência na formação inicial de professores. Cadernos de Pesquisa, São Paulo, v. 47, n. 166, p. 1166-1195, 2017. Disponível em: http://publicacoes. fcc.org.br/index.php/cp/article/view/4323. Acesso: 20 out. 2019.

FRANCO, Maria Amélia Santoro. Didática e pedagogia: da teoria de ensino à teoria da formação. In: EGGERT, Edla et al. (org.). Trajetórias e processos de ensinar e aprender: didática e formação de professores. Porto Alegre: PUCRS, 2008. p. 350-370.

FRANCO, Maria Amélia Santoro. Pedagogia da pesquisa-ação. Educação e Pesquisa, São Paulo, v. 31, n. 3, p. 483-502, 2005. Disponível em: http://goo.gl/mBbgRd. Acesso em: 1 abr. 2019. 
FRANCO, Maria Amélia Santoro. Pesquisa-ação: a produção partilhada de conhecimento. In: SILVA, Lázara Cristina da; MIRANDA, Maria Irene (org). Pesquisa-ação: uma alternativa à práxis educacional. Uberlândia: UFU, 2012. p. 51-70.

FRANCO, Maria Amélia Santoro; GUARNIERI, Maria Regina. Disciplina de didática: um estudo exploratório a partir dos planos de ensino. Pesquiseduca, Santos, v. 3, n. 5, p. 26-55, 2011. Disponível em: http://hdl. handle.net/11449/124736. Acesso em: 14 dez. 2021.

FREIRE, Paulo. Pedagogia do oprimido. Rio de Janeiro: Paz e Terra, 1984.

GOLDEMBERG, José. 0 repensar da educação no Brasil. Estudos Avançados, São Paulo, v. 7, n. 18, p. 65-137, 1993.

KALALI, Faouzia. Rapport au savoir: bilan sur la place du sujet dans les différents travaux. In: CONGRÈS INTERNATIONAL D'ACTUALITÉ DE LA RECHERCHE EN ÉDUCATION ET EN FORMATION, 2007, Strasbourg. Actes [...]. Strasbourg: Aecse, 2007. p. 1-8.

KINCHELOE, Joe L. A formação do professor como compromisso político: mapeando o pós-moderno. Porto Alegre: Artmed, 1996.

LIBÂNEO, José Carlos. 0 campo teórico e profissional da didática hoje: entre Ítaca e o canto das sereias. In: EGGERT, Edla et al. (org.). Trajetórias e processos de ensinar e aprender: didática e formação de professores. Porto Alegre: PUCRS, 2008. p. 234-252.

LIBÂNEO, José Carlos. 0 dualismo perverso da escola pública brasileira: escola do conhecimento para os ricos, escola do acolhimento social para os pobres. Educação e Pesquisa, São Paulo, v. 38, n. 1, p. 13-28, 2012.

MARCÍLIO, Maria Luiza. História da escola em São Paulo e no Brasil. São Paulo: Imprensa Oficial do Estado de São Paulo: Instituto Fernand Braudel, 2014.

MIGNOLO, Walter. A colonialidade de cabo a rabo: o hemisfério ocidental no horizonte conceitual da modernidade. In: LANDER, Edgardo (org.). A colonialidade do saber: eurocentrismo e ciências sociais: perspectivas latino-americanas. Buenos Aires: Clacso, 2005. p. 71-103.

PIMENTA, Selma Garrido; FRANCO, Maria Amélia Santoro; LIBÂNEO, José Carlos. Pedagogia, formação de professores - e agora? Problemas decorrentes das diretrizes curriculares nacionais para os cursos de pedagogia. In: DALBEN, Angela Imaculada Loureiro de Freitas et al. (org.). Convergências e tensões no campo da formação e do trabalho docente: avaliação educacional, educação à distância e tecnologias da informação e comunicação, educação profissional e tecnológica, ensino superior, políticas educacionais. Belo Horizonte: Autêntica, 2010. p. 831-852.

RIBEIRO, Djamila. Lugar de fala. São Paulo: Pólen, 2019. 
ROLNIK, Suely. "É preciso fazer um trabalho de descolonização do desejo". [Entrevista cedida a] Sarah Babiker. Revista IHU On-line. São Leopoldo: Instituto Humanitas Unisinos, 2019. Disponível em: http:// www. ihu.unisinos.br/78-noticias/591109-e-preciso-fazer-um-trabalho-de-descolonizacao-do-desejoentrevista-com-suely-rolnik. Acesso em: 20 set. 2020.

SAVIANI, Dermeval. Educação: do senso comum à consciência filosófica. 11. ed. Campinas: Autores Associados, 1996.

STRECK, Danilo Romeu. Descolonizar a participação: pautas para a pedagogia latino-americana. Educar em Revista, Curitiba, n. 2 (esp.), p. 189-202, 2017.

THOUARD, Denis. Qu'est-ce qu'une herméneutique critique. Methodos, Villeneuve d'Ascq, n. 2, 2002. Disponível em: http://goo.gl/rMPoJX. Acesso em: 21 maio 2019.

TSÉ-TUNG, Mao. Sobre a prática e a contradição. Apresentação Slavoj Sizek. Tradução José Maurício Gradel. Rio de Janeiro: Zahar, 2008.

Recebido em: 03.07.2020

Aprovado em: 01.09.2020

Maria Amélia Santoro Franco é pedagoga, doutora em educação e tem pós-doutorado em pedagogia. É líder do grupo de pesquisa Pedagogia Crítica: práticas e formação, e professora pesquisadora da Universidade Católica de Santos, pesquisadora 2 do CNPq. 